\title{
Growth factor TGF- $\beta$ induces intestinal epithelial cell (IEC-6) differentiation: miR-146b as a regulatory component in the negative feedback loop
}

\author{
Yalin Liao · Man Zhang • Bo Lönnerdal
}

Received: 26 November 2011/Accepted: 18 April 2012/Published online: 9 May 2012

(C) Springer-Verlag 2012

\begin{abstract}
TGF- $\beta$ is a potent pleiotropic factor that promotes small intestinal cell differentiation. The role of microRNAs in the TGF- $\beta$ induction of intestinal epithelial phenotype is largely unknown. We hypothesized that microRNAs are functionally involved in TGF- $\beta$-induced intestinal cell growth. In this study, TGF- $\beta$ caused a morphological change of IEC-6 cells and stimulated expression of the epithelial cell markers alkaline phosphatase, villin, and aminopeptidase N. By global microRNA profiling during TGF- $\beta$-induced intestinal crypt cell (IEC-6) differentiation, we identified 19 differentially expressed microRNAs. We showed by real-time Q-PCR that miR-146b expression increased rapidly after TGF- $\beta$ treatment; sequence analysis and in vitro assays revealed that miR146b targets SIAH2, an E3 ubiquitin ligase, with decreased protein expression upon IEC-6 cell differentiation. Transfection of miR-146b inhibitor before TGF- $\beta$ treatment blocked the down-regulation of SIAH2 in response to TGF- $\beta$. Moreover, SIAH 2 over-expression during TGF- $\beta$ treatment caused a significant decrease in Smad7 protein expression in IEC-6 cells. Furthermore, activation of the ERK1/2 pathway is active in the up-regulation of miR$146 \mathrm{~b}$ by TGF- $\beta$. These findings suggest a novel mechanism whereby TGF- $\beta$ signaling during IEC-6 cell differentiation may be modulated in part by microRNAs, and we propose
\end{abstract}

Y. Liao · M. Zhang · B. Lönnerdal $(\bowtie)$

Department of Nutrition, University of California,

One Shields Ave., Davis, CA 95616, USA

e-mail: bllonnerdal@ucdavis.edu

Present Address:

Y. Liao

Department of Genome Biology, The John Curtin School of Medical Research, The Australian National University, Canberra, ACT 0200, Australia a key role for miR-146b in the homeostasis of growth factor TGF- $\beta$ signaling through a negative feedback regulation involving down-regulation of SIAH2 repressed Smad7 activities.

Keywords IEC-6 cell - TGF- $\beta$ - Differentiation · miR-146b $\cdot$ microRNA array $\cdot$ SIAH2

\section{Introduction}

The mammalian small intestinal mucosa is a complex unit with a turnover rate of 5-7 days, and this homeostasis is tightly regulated. In response to extracellular cues, the intestinal local stem cells on the basolateral side of the crypts undergo proliferation, and differentiate into the four functional differentiated cell types: enterocytes, enteroendocrine cells, goblet cells, and Paneth cells (Cheng and Leblond 1974; van der Flier and Clevers 2009). Understanding the molecular mechanisms that govern intestinal differentiation would not only greatly aid in defining the important molecular events during development, but also provide valuable information to target aberrantly expressed molecules in pathological conditions.

Quaroni et al. first established the IEC-6 cell line and demonstrated by ultrastructural and immunochemical studies that it has features of undifferentiated small intestinal crypt cells (Quaroni et al. 1979). Since then, IEC-6 cells have been extensively used to examine the molecular mechanisms of intestinal cell differentiation (Gendron et al. 2006; Koo et al. 2009; Olson et al. 1991; Wood et al. 2003). Specifically, TGF- $\beta$ (Barnard et al. 1989), mixtures of exogenous nucleosides (thymidine + cytidine + guanosine + inosine or uridine + cytidine + guanosine + inosine) (Rodríguez-Serrano et al. 2010), TNF- $\alpha$, IFN- $\gamma$ 
(Kolinska et al. 2008), gastrin (Wang et al. 2003), and Matrigel (Carroll et al. 1988) have been reported to effectively induce IEC-6 cell differentiation.

TGF- $\beta$ is a pleiotropic cytokine which functions as a tumor suppressor and proliferation inhibitor in the small intestinal epithelium; dysregulation (inhibition or overexpression) of TGF- $\beta$ can result in uncontrolled growth and tumor formation (Wharton and Derynck 2009). Mammalian milk contains TGF- $\beta$ s that are important for the maintenance of intestinal homeostasis in the newborn (Lönnerdal 2010; Penttila 2010). In its signaling pathway, TGF- $\beta$ ligands induce complex formation between type I and type II serine/threonine kinase receptors, and intracellular signaling is subsequently initiated by the activated type I receptor. Receptor-regulated Smad proteins (R-Smad) (Smad2 and Smad3) are a class of intracellular signaling molecules mediating the downstream effects of TGF- $\beta$. After being activated, R-Smads form a complex with Smad4. The resulting Smad complex translocates into the nucleus to associate with chromatin and thus regulate transcription (Sancho et al. 2004). The negative regulation of the TGF- $\beta$ signaling pathway is equally important to achieve a tight biological balance, and the antagonism could occur via inhibitory (I) Smads (Smad6 and Smad7), or inhibition of Smad transcriptional function. I-Smads compete with R-Smad to bind to cell surface receptors, recruit phosphatases and E3 ubiquitin ligases to degrade cell surface receptors, or prevent Smad complex formation; the Smad interactors and Smad transcriptional co-repressors, such as SnoN, TIF1 $\gamma$, Ski, etc. directly sequester Smad signals (Itoh and ten Dijke 2007; Miyazono 2000).

microRNAs have recently been suggested to be critical regulatory components in TGF- $\beta$ signaling. Specifically for the differentiation stimulating effects of TGF- $\beta$, there have been reports on muscle cells (Sun et al. 2008), human adipose tissue stem cells (Kim et al. 2009), liver stem cells (Rogler et al. 2009), and bone marrow-derived ST2 stromal cells (Mizuno et al. 2009). The mechanisms by which microRNAs play their roles in mediating TGF- $\beta$-induced cell differentiation in small intestinal crypt cells, however, are poorly addressed.

The objective of this study was to identify these microRNA(s) and their involvement in molecular pathways during TGF- $\beta$-induced IEC- 6 cell differentiation.

\section{Materials and methods}

Cell culture

IEC-6 cells (rat small intestinal epithelial cells) and HEK293 (human embryonic kidney 293) cells were maintained as described by Liao and Lönnerdal (2010a, b, c).
For hematoxylin \& eosin (H\&E) staining, IEC-6 cells were grown on sterile glass coverslips at $50 \%$ confluency in 24-well plates on top of cover slips, and treated with $50 \mathrm{ng} / \mathrm{ml}$ TGF- $\beta$ (R\&D Systems). Controls were treated with the same growth medium without TGF- $\beta$. After $48 \mathrm{~h}$, the coverslips were removed and fixed with $4 \%$ paraformaldehyde in $1 \times$ phosphate-buffered saline (PBS) for $15 \mathrm{~min}$ at room temperature, washed with $1 \times$ PBS three times, at $5 \mathrm{~min}$ each, followed by H\&E staining and examination under a light microscope (Olympus, 40x).

For miR-146b LNA inhibitor transfection and SIAH2 over-expression, IEC- 6 cells were seeded at $50 \%$ confluency per 6-well the day prior to transfection with $50 \mathrm{nM}$ miR-146b inhibitor (Thermo Scientific) or $100 \mathrm{ng} / \mathrm{ml}$ pCMV-SPORT6-SIAH2 expression DNA (Open Biosystems). Cells were then treated with $50 \mathrm{ng} / \mathrm{ml}$ TGF- $\beta$ and collected $48 \mathrm{~h}$ after transfection for immunoblotting analyses. The control group was treated with $1 \times$ PBS alone.

For ERK1/2 signaling pathway analyses, IEC-6 cells were seeded at $50 \%$ confluency per 6-well the day prior to the experiment, $50 \mathrm{ng} / \mathrm{ml}$ TGF- $\beta$ with or without $10 \mu \mathrm{M}$ selective inhibitor of MEK1 and MEK2 U0126 (dissolved in DMSO) were used to treat the cells, and cell proteins were collected at $0,5,10,30$, and $60 \mathrm{~min}$ after treatment to analyze ERK1/2, p-ERK1/2 expression. All transfections were performed with Lipofectamine 2000 (Invitrogen) according to the manufacturer's recommendations.

\section{Bioinformatics analysis}

The mature sequence of miR-146b (5'-UGAGAACUGAA UUCCAUAGGCUGU- $3^{\prime}$ ) was retrieved from the miRBase Sequence Database, release 14 (http://microrna.sanger.ac. uk/sequences/), and mRNA 3'UTRs of SIAH2 from human, mouse, rat, and chimpanzee were aligned with the miR-146b sequence using the ClustalW program (http:// www.ebi.ac.uk/Tools/clustalw/index.html).

The miR-146b gene targets were predicted from the MicroCosm Targets Version 5 (http://www.ebi.ac.uk/ enright-srv/microcosm/cgi-bin/targets/v5/search.pl).

\section{MicroRNA array}

RNA integrities were examined on Bioanalyzer at the University of California, Davis Genome Center. miRNA microarray was performed at the J. David Gladstone Institute Genomics Core facility, University of California, San Francisco (http://www.gladstone.ucsf.edu/gladstone/ $\mathrm{php} /$ ?sitename= $=$ genomicscore) .

An amount of 300 ng of each RNA sample was labeled with $\mathrm{Cy} 5$ or $\mathrm{Cy} 3$ using miRCURY LNA miRNA array Power Labeling kit (Exiqon). Hybridization SureHyb chamber kit and Gasket slide kit (Agilent) were used to 
hybridize the labeled RNA for $18 \mathrm{~h}$ onto Exiqon miRCURY LNA miRNA array V.11.0 (miRBase Sequence Database, http://microrna.sanger.ac.uk/sequences, release 11.0). This array contains 9,360 probes, 3,300 of which represent 825 human miRNAs with 4 duplicate probes per miRNA, additional 1,400 probes for miRNA in mouse or rat and 472 probes for miRNA in human/mouse viruses. In addition, there is a variety of controls and other probes: 1,640 empty, 476 spike_controls, 28 negative controls, 12 U6-snRNA, 60 hsa_SNORD, 1,728 miRPlus, 4 5SrRNA, and 240 Hy3. For each group, 3 arrays were performed, and 1 array was dye-swapped. Arrays were scanned on an Axon GenePix 4000B scanner, and GPR files containing fluorescent ratios (TGF-beta-treated/untreated) were generated using GenePix Pro 6.0 software. Print tip loess normalization was used within arrays. The values for each miRNA are the $\log 2$ of median summarized PTL.

Vector construction

A 1,018 bp fragment of the SIAH2 mRNA 3'UTR (corresponding to nt 1,603-2,620 of the Entrez PubMed transcript NM_005067) was PCR-amplified from a pCMV-SPORT6 vector containing SIAH2 full length cDNA (Open Biosystems); the PCR products were cloned into pGL3-control luciferase reporter vector (Promega) via an $\mathrm{XbaI}$ restriction site, immediately downstream of the luciferase gene.

\section{Luciferase assay}

For luciferase assays, HEK293 cells were seeded at $70 \%$ confluency per 96-well $6 \mathrm{~h}$ prior to transfection with $250 \mathrm{ng}$ luciferase expression construct and 50-200 nM miR-146b mimic (Thermo Scientific). Mock transfected cells were transfected with luciferase expression construct alone. cel-miR-67 (Thermo Scientific) served as a negative control for miR-146b mimic. Luciferase activities were measured $24 \mathrm{~h}$ after transfection using the Dual Glo Luciferase Assay System (Promega), and pGL4.73[hRluc/ SV40] vector (Promega) was used as internal reference.

\section{Real-time Q-PCR}

Total RNA from cultured IEC-6 cells was isolated using miRNeasy Mini Kit (Qiagen) and diluted to $2 \mu \mathrm{g} / \mu \mathrm{l}$ in DEPC-treated nuclease-free water (Ambion Inc.).

For miR-146b assay, cDNA was generated from $2 \mu \mathrm{g}$ RNA using TaqMan ${ }^{\circledR}$ MicroRNA Reverse Transcription Kit (Applied Biosystems) according to the manufacturer's protocol. The miR-146b gene-specific stem-loop RT primer for reverse transcription was designed according to
miRNAs sequences listed in the Sanger miRBase (http:// microrna.sanger.ac.uk/sequences/).

For intestinal epithelial cell marker gene assays, cDNA was generated from $2 \mu \mathrm{g}$ RNA using a High Capacity cDNA Reverse Transcription kit (Applied Biosystems). Gene-specific primers were chosen using Primer Express software (Applied Biosystems) to span exons in order to avoid co-amplification of genomic DNA: alkaline phosphatase, sense primer $5^{\prime}$-CAGCCACCGCCTATCTCTGT-3', antisense primer $5^{\prime}$-TGCTGTTGCACTGGTTGAATC-3'; villin, sense primer $5^{\prime}$-GCAGCTGCCATCTACACAACA-3', antisense primer $5^{\prime}$-CGCTCTCATGGCCTTGGA-3'; aminopeptidase $\mathrm{N}$, sense primer $5^{\prime}$-TTTCTTCTTGGCCTGAG CTGTT-3', antisense primer 5'-TGTAGAAACCCTTGGC CATGA-3'; GAPDH sense primer 5'-GGTGTGAACCAC GAGAAATA-3' ${ }^{\prime}$, antisense primer $5^{\prime}$-TGAAGTCACAGG AGACAACC- $3^{\prime}$; and SIAH2 sense primer $5^{\prime}$-TGCCTTGT TTTTGACACAGC-3', antisense primer $5^{\prime}$-AGTTGTGGG TCCTGACTTGG-3'.

The RT reaction and PCR reaction for miRNA and marker genes were performed as previously described (Liao and Lönnerdal 2010a, b, c). Each sample was normalized to U87 for miR-146b and GAPDH for epithelial cell markers, using the following equation: $\Delta \mathrm{Ct}_{\mathrm{GENE}}=$ $\mathrm{Ct}_{\mathrm{GENE}}-\mathrm{Ct}_{\mathrm{U} 87 / \mathrm{GAPDH}}$. The fold change, relative to the control group, was calculated using the following equation: $2^{(\Delta \Delta \mathrm{CtGENE})}$ where $\Delta \Delta \mathrm{CtGENE}=\Delta \mathrm{Ct}_{\mathrm{GENE}}$ of U87/GAP$\mathrm{DH}-\Delta \mathrm{Ct}_{\mathrm{GENE}}$ of each well.

Immunoblotting analysis

IEC-6 cells upon different treatments were homogenized in RIPA buffer (25 mM Tris- $\mathrm{HCl} \mathrm{pH} \mathrm{7.6,} 150 \mathrm{mM} \mathrm{NaCl}$, $1 \%$ NP-40, $1 \%$ sodium deoxycholate and $0.1 \%$ SDS) containing $1 \times$ complete EDTA-free protease inhibitor (Roche). Fifty micrograms of proteins was electrophoresed through $10 \%$ polyacrylamide gel, transferred onto nitrocellulose membrane at $350 \mathrm{~mA}$ for $60 \mathrm{~min}$, and blocked overnight in $1 \times \mathrm{PBS} / 0.1 \%$ Tween-20 (PBST) with $5 \%$ non-fat milk at $4{ }^{\circ} \mathrm{C}$.

Antibodies against SIAH2 and Smad7 were from Novus Biologicals; antibodies against ERK1/2 and p-ERK1/2 were from Cell Signaling Technology. Bands were detected using Super Signal Femto chemiluminescent reagent (Pierce) and quantified using the Chemi-doc gel quantification system (Bio-Rad). All data were normalized to $\beta$-actin.

Data analysis

microRNA microarray data were analyzed according to methods described earlier (Liao and Lönnerdal 2010a, b, c). Raw and processed miRNA profile data were deposited 
in the gene expression omnibus (GEO) database (Edgar et al. 2002) with accession number GSE20982 (http://www. ncbi.nlm.nih.gov/geo/query/acc.cgi?acc=GSE20982).

All other data were analyzed by Prism (Prism GraphPad Software). The effects of TGF- $\beta$ treatment on miR-146b expression in IEC-6 cells, miR-146b inhibitor on SIAH2 protein expression in IEC-6 cells, SIAH2 over-expression on Smad7 protein expression, and the effect of miR-146b mimic on luciferase activity in HEK293 cells were tested by one-way ANOVA; Tukey's test was performed to compare all columns; the effects of U0126 on p-ERK1/2 expression and mutant ERK vector transfection on miR$146 \mathrm{~b}$ expression were tested by two-tailed Student's $t$ test. Data are shown as means \pm SEM of three independent experiments. Differences were considered significant when $P<0.05$.

\section{Results}

TGF- $\beta$ induces IEC- 6 cell differentiation

The functional outcomes of TGF- $\beta$ treatment were analyzed by H\&E staining and real-time Q-PCR. Firstly, TGF- $\beta$-treated cells contain more abundant cytoplasm, have larger size and smaller numbers of nucleoli. Cellular connections formed around the cytoplasm resulting in well-delineated cell borders. In certain areas, cells showed epithelial cell morphology. Cells in the control group contained sparse cytoplasm, small but abundant nucleoli which are related to the active division ability, and the cytoplasm does not have clear cell boundaries to the extracellular space. Compared with the even distribution of the treated group, the control cells tend to aggregate in certain areas (Fig. 1a). Secondly, treatment of IEC-6 cells

\section{A}
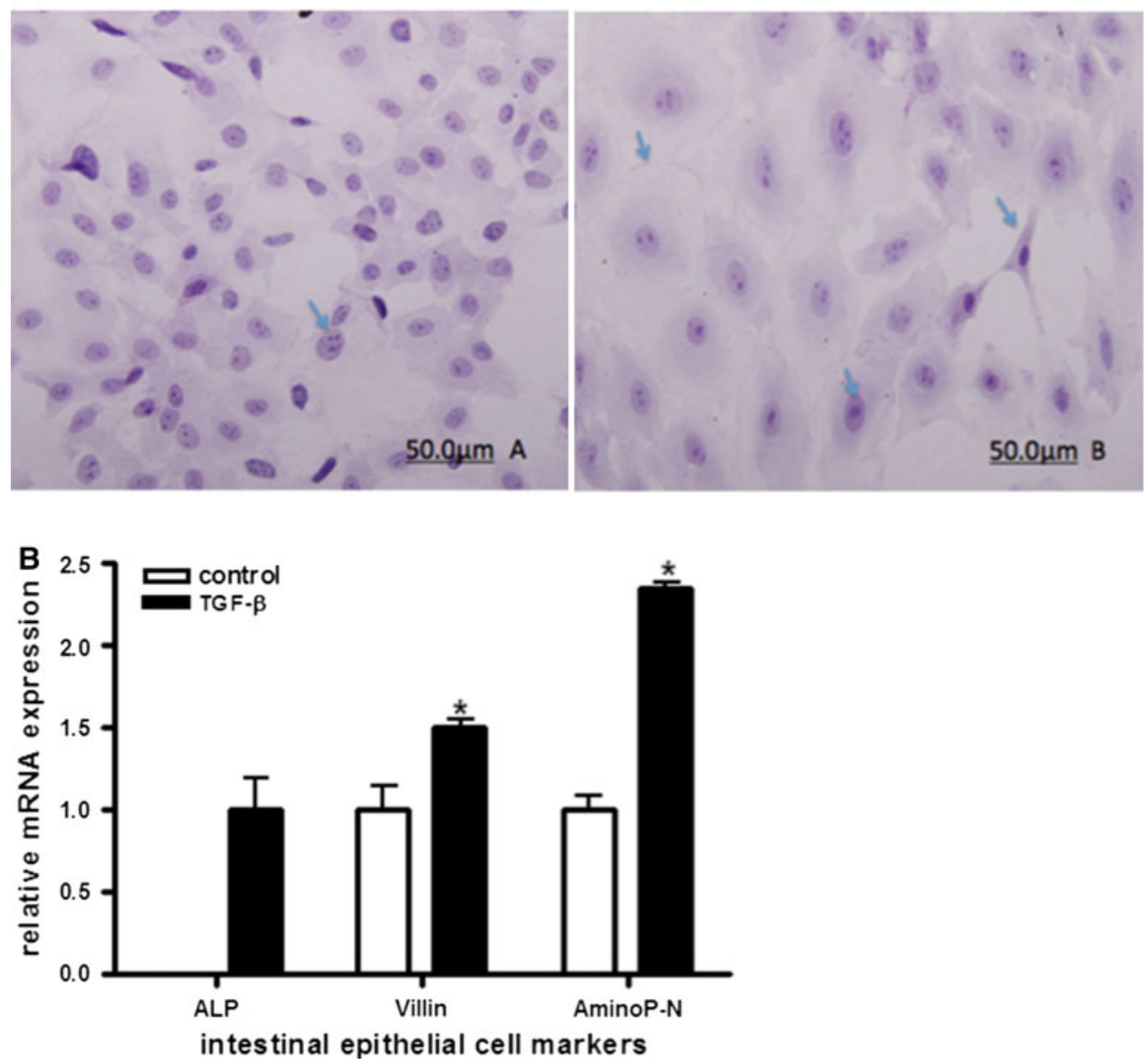

Fig. 1 TGF- $\beta$ induces IEC-6 cell differentiation. IEC-6 cells in 6-well plates were treated with $50 \mathrm{ng} / \mathrm{ml}$ TGF- $\beta$, and the control group was grown in growth media alone. After $48 \mathrm{~h}$ treatment, cell morphology and mRNA expression of intestinal epithelial cell markers were analyzed by H\&E staining and real-time Q-PCR, respectively. a Cell morphology. Treated cells are distributed more evenly, contain more abundant cytoplasm, and have larger size and smaller numbers of nucleoli. Cells also showed intercellular connections around the cytoplasm and well-delineated cell borders, indicating epithelial cell morphology. Cells in the control group tended to aggregate and contained sparse plasma, small but many nucleoli that are related to the active division ability; b Gene expression. TGF- $\beta$ significantly up-regulated the mRNAs for alkaline phosphatase, villin, and aminopeptidase $\mathrm{N}(P<0.05)$. Values are means \pm SEM run in triplicates; asterisks indicate significant differences between TGF- $\beta$ treatment and control groups 
with TGF- $\beta$ for $48 \mathrm{~h}$ significantly stimulated the expression of the following intestinal epithelial cell markers: villin ( $1.50 \pm 0.09$ vs. $1.00 \pm 0.29, P<0.05)$ and aminopeptidase $N(2.35 \pm 0.08$ vs. $1.00 \pm 0.16, P<0.01)$. Alkaline phosphatase readily detected after TGF- $\beta$ treatment was undetectable prior to treatment (Fig. 1b). Therefore, $48 \mathrm{~h}$ after treatment was selected to examine expression of microRNAs during TGF- $\beta$ stimulation of IEC- 6 cells.

microRNAs are differentially regulated during TGF- $\beta$ stimulated IEC-6 cell differentiation

We used Exiqon miRNA microarray v11.0 to determine the expression levels of mature miRNAs purified from
IEC- 6 cells before and after $50 \mathrm{ng} / \mathrm{ml}$ TGF- $\beta$ stimulated cell differentiation. Among all the screened individual miRNAs, 14 miRNAs were significantly upregulated, including miR-146b, miR-23b, miR-26a, and miR-182, whereas 5 were down-regulated (Fig. 2a). miR-146b showed the most substantial up-regulation over the course of $48 \mathrm{~h}$ as indicated by the arrow in the MA plots (Fig. 2b). The raw data are deposited in Gene Expression Omnibus (GEO, http://www.ncbi.nlm.nih.gov/geo/), with accession number GSE20133. Table 1 lists all 19 differentially regulated miRNAs and their respective fold changes. Among these, 5 were significantly down-regulated and 14 were significantly up-regulated upon TGF- $\beta$ treatment.
Fig. 2 microRNAs are regulated during TGF- $\beta$ stimulated IEC- 6 cell differentiation. a Microarray analysis identified 19 miRNAs that significantly correlated with IEC-6 cell differentiation upon TGF- $\beta$ treatment. Hierarchical clustering analysis was performed using Euclidian distance. Each row represents the relative levels of expression for a significantly regulated single microRNA, and each column represents the relative expression level of biological replicate relative to the untreated control $(P<0.01)$. Red color of treatment group represents upregulation versus control, and green color of treatment group represents downregulation; b The MA plot shows averaged, backgroundsubtracted fold change ( $Y$ axis) and average expression intensity ( $X$ axis) of each probe, on both channels for Cy-3-labeled control and Cy-5-labeled treated cells and their dye-swaps. Each dot (insignificantly regulated) or triangle (significantly regulated) represents one miRNA probe. Arrow indicates the miR-146b probe

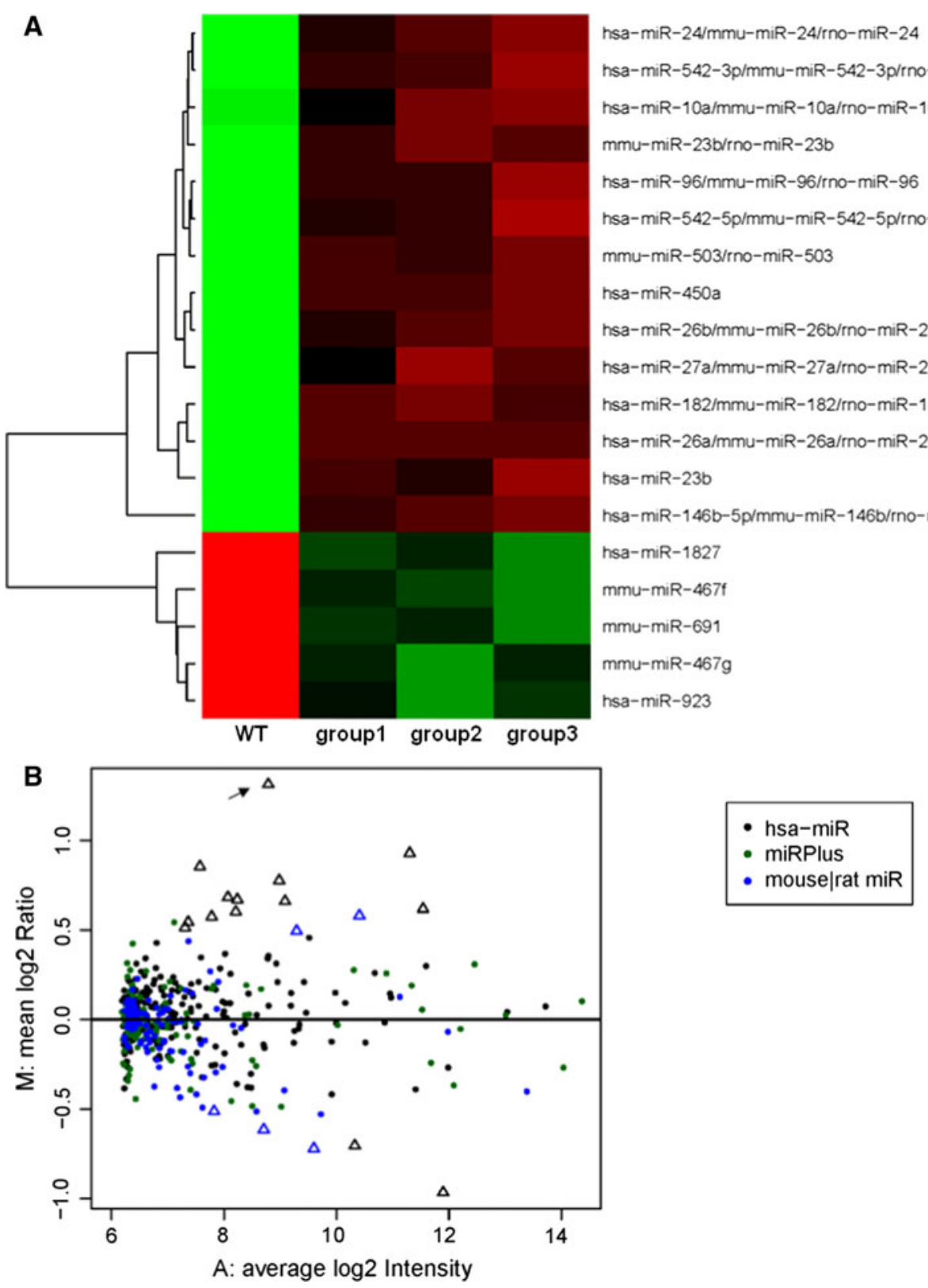


Table 1 Fold change of differentially regulated miRNAs during TGF- $\beta$-induced IEC- 6 cell differentiation

\begin{tabular}{lll}
\hline microRNA & Fold change versus control & $P$ value \\
\hline hsa-miR-146b-5p & 2.48 & 0.0009 \\
hsa-miR-23b & 1.90 & 0.0025 \\
hsa-miR-182 & 1.81 & 0.0022 \\
hsa-miR-26a & 1.71 & 0.0022 \\
hsa-miR-27a & 1.60 & 0.005 \\
hsa-miR-450a & 1.59 & 0.004 \\
hsa-miR-26b & 1.58 & 0.004 \\
hsa-miR-24 & 1.53 & 0.005 \\
hsa-miR-542-3p & 1.52 & 0.005 \\
mmu-miR-23b & 1.49 & 0.005 \\
hsa-miR-10a & 1.49 & 0.009 \\
hsa-miR-96 & 1.46 & 0.007 \\
hsa-miR-542-5p & 1.43 & 0.01 \\
mmu-miR-503 & 1.41 & 0.008 \\
hsa-miR-1827 & 0.51 & 0.002 \\
mmu-miR-691 & 0.61 & 0.004 \\
hsa-miR-923 & 0.61 & 0.005 \\
mmu-miR-467 g & 0.65 & 0.007 \\
mmu-miR-467f & 0.70 & 0.008 \\
\hline
\end{tabular}

miR-146b is regulated in the TGF- $\beta$ signaling pathway in a time-dependent manner

Analysis by real-time Q-PCR confirmed the presence of miR-146b in IEC-6 cells and unveiled a distinct pattern of induction in response to TGF- $\beta$ treatment.

miR-146b continuously increased during the first $6 \mathrm{~h}$ after treatment $(1.33 \pm 0.64$ vs. $1.00 \pm 0.13$ at $3 \mathrm{~h}$; $2.56 \pm 0.07$ vs. $1.00 \pm 0.13$ at $6 \mathrm{~h}$ compared to $0 \mathrm{~h}$ ) and remained at a plateau from $6 \mathrm{~h}$ until $48 \mathrm{~h}$ after treatment (Fig. 3). Because miR-146b expression peaked at approximately $6 \mathrm{~h}$ after TGF- $\beta$ treatment, we examined miR-146b at this time point in subsequent experiments.

\section{SIAH2 is a putative target for miR-146b}

To identify putative miR-146b target genes, we first retrieved the 941 predicted gene targets from the MicroCosm Targets Database. The mRNA sequences of the genes were manually analyzed, and the result showed that in the SIAH2 mRNA $3^{\prime} \mathrm{UTR}$, sequences complementary to the seed region of miR-146b were well conserved between human, mouse, rat, and chimpanzee (Fig. 4a). Further, luciferase reporter assay in HEK293 cells revealed that miR-146b mimic co-transfection could repress the luciferase activity generated by luciferase vector containing the

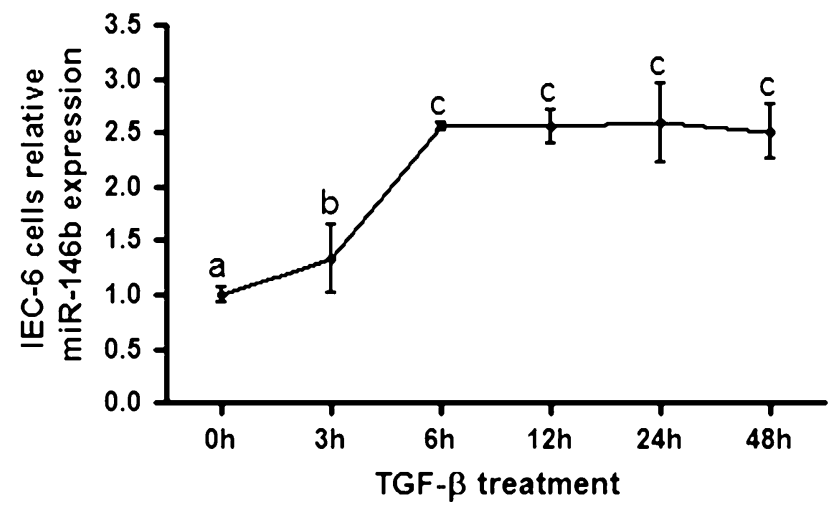

Fig. 3 miR-146b is regulated in the TGF- $\beta$ signaling pathway in a time-dependent manner. Real-time Q-PCR analysis of miR-146b expression during $48 \mathrm{~h}$ of TGF- $\beta$ treatment of IEC- 6 cells. Data were normalized to U87 levels, and values are means \pm SEM run in triplicates; letters indicate significant differences between time points

mRNA $3^{\prime}$ UTR of SIAH2 in a dose-dependent manner. The negative control cel-miR-67 did not result in any significant reductions in luciferase activity, demonstrating binding activity between the miR-146b sequence and SIAH2 mRNA (Fig. 4b). Furthermore, the down-regulation of SIAH2 protein was significantly blocked when miR-146b inhibitor is present in response to TGF- $\beta$ compared to cells treated with TGF- $\beta$ alone (Fig. $4 \mathrm{c}$ ), indicating SIAH2 is downstream of miR-146b in the cellular context; as a consequence of TGF- $\beta$ intervention, SIAH 2 mRNA transcripts decreased by $30 \%$ while its protein level decreased by $20 \%(P<0.05)$, and miR-146b inhibitor restored the SIAH2 mRNA expression to the level without TGF- $\beta$ (Fig. 4c), this observation implies that mechanistically, miR-146b regulates SIAH2 mRNA primarily through inducing transcript decay.

Smad7 is a downstream effector of SIAH2 during TGF- $\beta$ induced IEC- 6 cell differentiation

To identify the downstream effector of SIAH2 during TGF- $\beta$-induced IEC- 6 cell differentiation, we transiently over-expressed SIAH2 protein in IEC-6 cells. Compared to untreated cells, TGF- $\beta$ induced a significant decrease in SIAH2 protein $(0.51 \pm 0.04$ vs. $1.00 \pm 0.15)$ and a significant increase in $\mathrm{Smad} 7$ protein $(3.03 \pm 0.44$ vs. $1.00 \pm 0.18$ ). During the course of differentiation induction (shown by the up-regulation of ALP, villin, and aminopeptidase $\mathrm{N}$, as in Fig. 1b), compared to mock transfected cells, SIAH2 over-expression $(0.89 \pm 0.05$ vs. $0.60 \pm 0.02)$ significantly blocked the up-regulation of Smad7 total protein $(1.78 \pm 0.06$ vs. $3.05 \pm 0.08)$ (Fig. 5). 


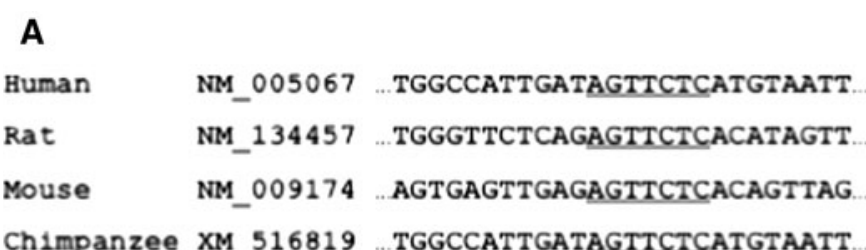

m1R146b 3'UCGGAUACCUUAAGUCAAGAGUS *

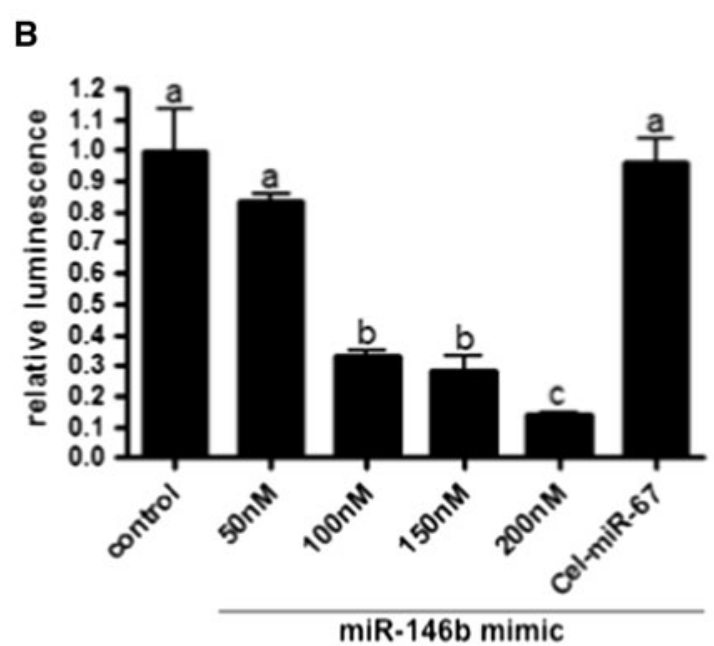

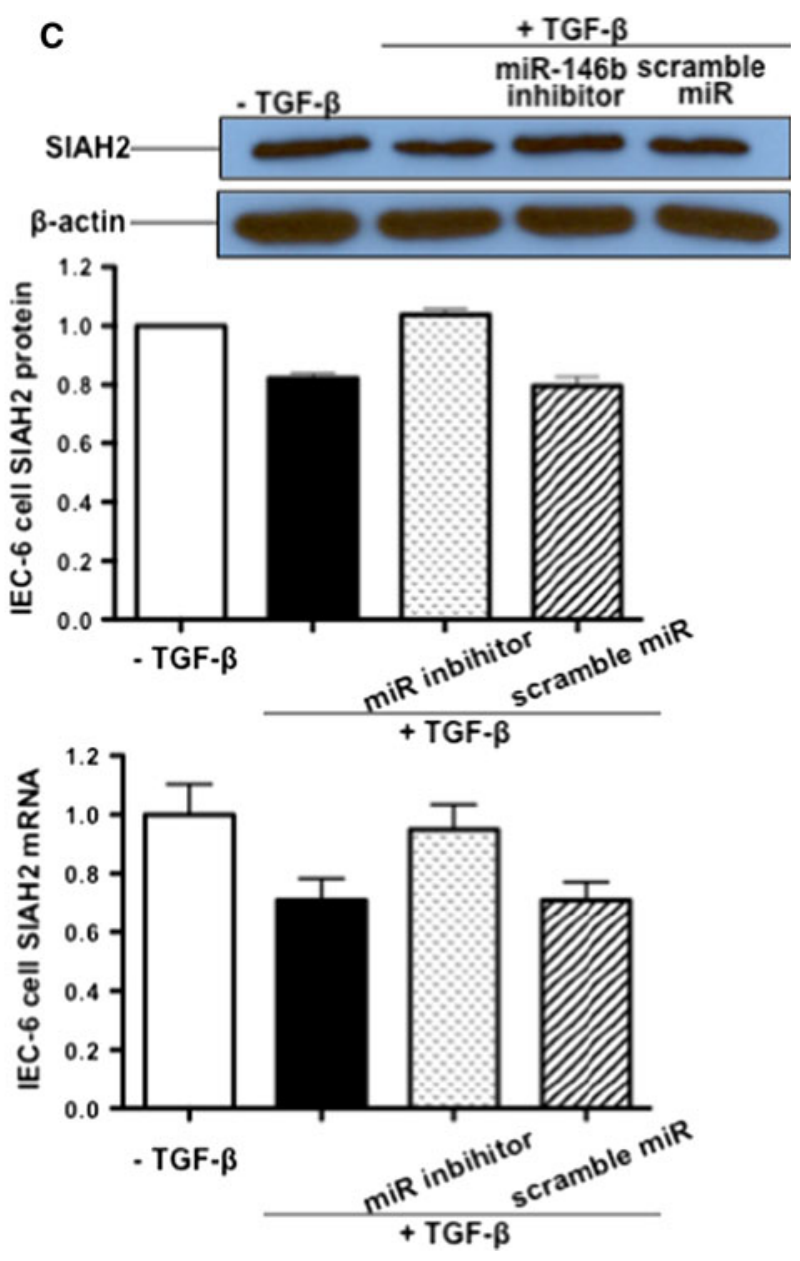

analyzed 24 h post-transfection. A structurally unrelated miRNA (celmiR-67) served as a negative control. c IEC-6 cells were treated with $50 \mathrm{ng} / \mathrm{ml}$ TGF- $\beta$ with or without transfection with miR-146b inhibitor before treatment. After $48 \mathrm{~h}$ treatment, total SIAH 2 protein and mRNA transcripts were analyzed by immunoblotting and real-time Q-PCR, respectively. Values are means \pm SEM run in triplicates; letters indicate significant differences between treatment groups $(P<0.05)$

signaling molecules. TGF- $\beta$ has long been suggested to stimulate cellular differentiation, and it was demonstrated that positive and negative signals are of equal significance to achieve a tightly regulated onset and termination of TGF- $\beta$ signaling (Moustakas and Heldin 2009). The present study clearly demonstrated that miR-146b is actively induced upon TGF- $\beta$-stimulated IEC- 6 differentiation, and that this induction targets SIAH2 to release Smad7 activity and requires ERK1/2 activation.

Proteosomal degradation of proteins by the ubiquitin pathway is an important mechanism to maintain cellular homeostasis. The ubiquitylation process involves covalent attachment of ubiquitin to the substrate by three enzymes: ubiquitin E1 activating enzyme, E2 ubiquitin-conjugating enzymes, and E3 ubiquitin ligases, see review (Weissman 2001). SIAH1 (282 amino acids) and SIAH2 (324 amino acids) are the human members of an evolutionary highly
The strict regulation of small intestinal cell differentiation requires elaborate interactions between a variety of 

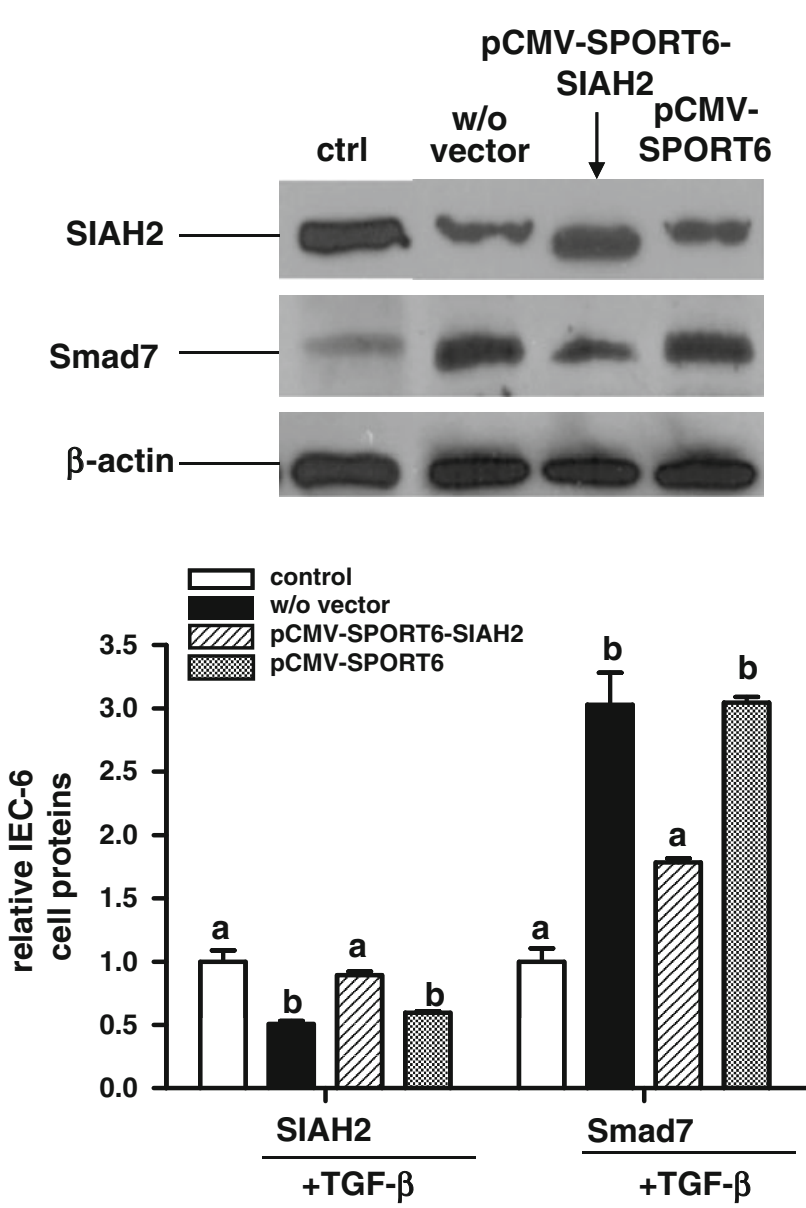

Fig. $5 \mathrm{Smad} 7$ is a downstream effector of SIAH2. pCMV-SPORT6SIAH2 vector was transfected into IEC-6 cells prior to TGF- $\beta$ treatment. After $36 \mathrm{~h}$ transfection, total Smad7 protein was analyzed by immunoblotting. Over-expression of SIAH2 was confirmed by immunoblotting. Values are means \pm SEM run in triplicates; letters indicate significant differences between treatment groups $(P<0.05)$

conserved E3 ubiquitin ligase, sharing $76 \%$ sequence homology. Human SIAH1 and SIAH2 have overlapping functions and recognize similar substrates (House et al. 2009).
SIAH1 is known to be involved in apoptosis and tumor suppression (Germani et al. 2003), and recently SIAH1 was also suggested to indirectly target TGF- $\beta /$ Smad transcription, thus modulating duration and magnitude of the TGF- $\beta$ signal in C2C12 mouse myoblast cells (Johnsen et al. 2002).

miR-146b is highly conserved among vertebrates (http:// www.mirbase.org/cgi-bin/mirna_summary.pl?fam=MIPF $0000103)$ and shares an identical seed sequence $\left(5^{\prime} \mathrm{GAG}\right.$ AACU3'). Importantly, the miR-146b gene in human, rat, and chimpanzee are located on the positive strand on the same chromosome (Chr10), implicating substantial roles it may have in targeted biological processes. There have been other recent studies on the functions of miR-146b, but with conflicting results. For example, up-regulation of miR146b could inhibit the metastasis of breast cancer (Hurst et al. 2009), and glioma (Xia et al. 2009). A number of other studies observed over-expression of miR-146b in cancer (Melkamu et al. 2010; Chen et al. 2008; Fulci et al. 2009). The stimulatory effect of TGF- $\beta$ on differentiation of intestinal epithelial cells is closely associated with its tumor suppressing effects; therefore, it is of significance to examine whether and how miR-146b is involved in this important biological process.

Studies have shown that base-pairing to the microRNA seed region is critical for target mRNA recognition (Doench and Sharp 2004; Brennecke et al. 2005). By means of bioinformatics approaches, miR-146b was found to possess $100 \%$ base-pairing with the SIAH 2 seed region from human, mouse, rat, and chimpanzee and partial basepairing with the surrounding regions. Furthermore, luciferase assay in HEK293 cells (Fig. 4b) and miR-146b inhibitor transfection in IEC-6 cells during TGF- $\beta$ stimulation (Fig. 4c) suggest that the seed match to miR-146b confers functional repression of the SIAH2 gene. miR146b inhibitor transfection alone in IEC-6 cells also had stimulating effects on SIAH2 protein expression, indicating a regulatory relationship between the two molecules.
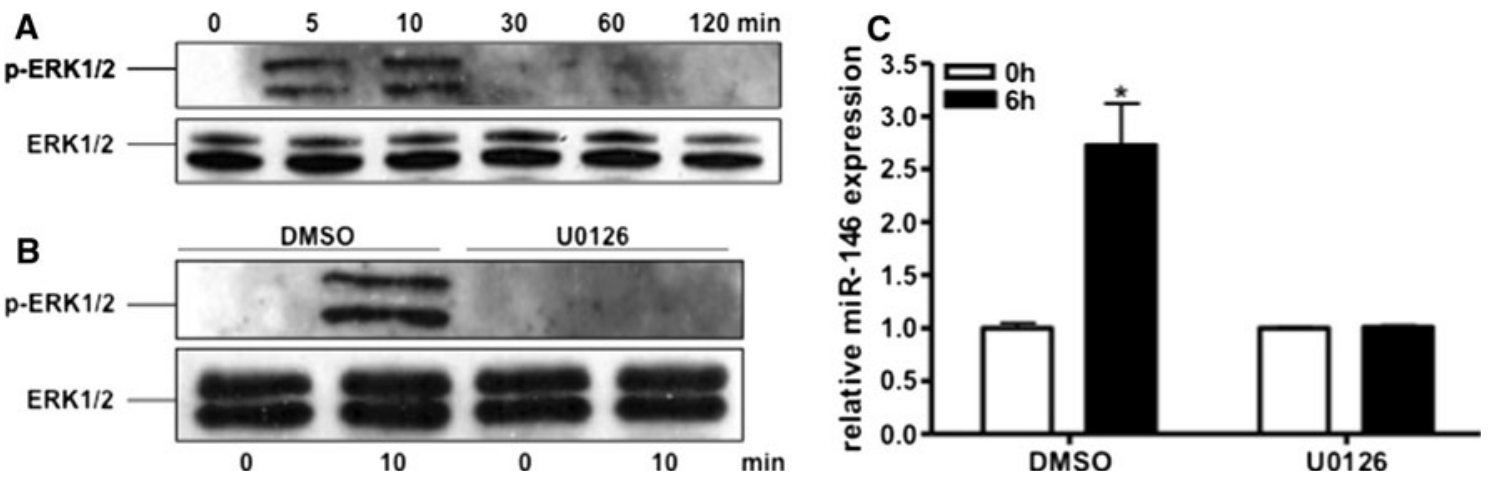

Fig. 6 Activation of the ERK1/2 pathway is involved in TGF- $\beta$ induced miR-146b up-regulation during IEC- 6 cell differentiation. a IEC- 6 cells were treated with $50 \mathrm{ng} / \mathrm{ml}$ TGF- $\beta$ for the indicated times, and cells were analyzed for ERK1/2 and p-ERK1/2 by

immunoblotting. b, c IEC-6 cells were pre-treated with $10 \mu \mathrm{M}$ U0126 for $15 \mathrm{~min}$ before treatment with $50 \mathrm{ng} / \mathrm{ml}$ TGF- $\beta$ for $6 \mathrm{~h}$. U0126 inhibition of p-ERK1/2 was confirmed by immunoblotting (b) and miR-146b expression was observed by real-time Q-PCR (c) 


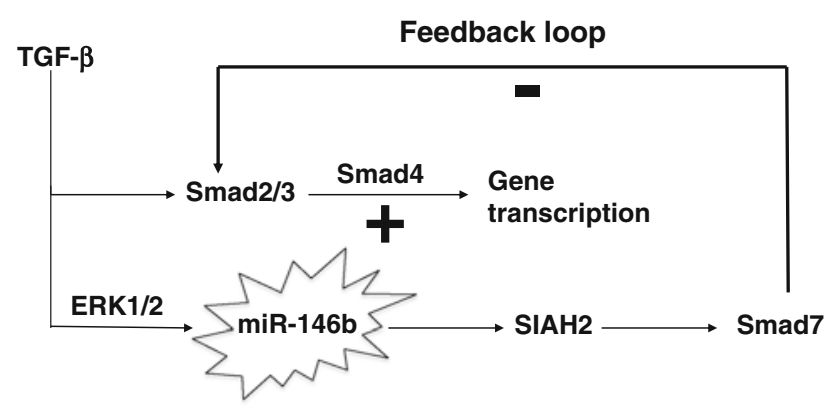

Fig. 7 Schematic illustration of miR-146b function in IEC-6 cells mediating TGF- $\beta$ signaling. It is known that the stimulatory Smad $2 / 3$ form complex with Smad4 as an immediate consequence of TGF- $\beta$ stimuli; up-regulation of miR-146b (involving ERK1/2 activation) directly causes the abundance of SIAH2 functional protein to decrease, which releases of the inhibitory $\operatorname{Smad} 7$ to negatively regulate the activities of stimulatory Smads, thus maintaining the homeostasis of TGF- $\beta$ signaling pathway

Smad7 is a $46-\mathrm{kD}$ protein, which participates in the negative feedback loop to control TGF- $\beta$ responses. Smad 7 is rapidly induced upon TGF- $\beta$ stimulation and binds to the TGF- $\beta$ receptor complex, inhibiting TGF- $\beta$-mediated phosphorylation of Smad2 and Smad3 (Nakao et al. 1997). In fact, Smad7 was suggested to be a key molecular switch that negatively regulates TGF- $\beta$ signaling in the trabecular meshwork (Fuchshofer et al. 2009). In this study, we overexpressed SIAH2 protein in IEC-6 cells by transfecting SIAH2 expressing DNA driven by a CMV promoter before TGF- $\beta$ treatment. Notably, the abundance of Smad7 protein was down-regulated in response to up-regulation of SIAH2, providing evidence that $\operatorname{Smad} 7$ is a putative downstream effector of SIAH2.

The ERK1/2 signaling pathway is well known to play pivotal roles in the differentiation of a variety of cell types, including human marrow-derived mesenchymal stem cells (Chang et al. 2008), human trophoblasts (Daoud et al. 2005), and postnatal neural stem cells (Hu et al. 2004). Importantly, ERK MAP kinase was also suggested to crosstalk with TGF- $\beta$ signaling pathway components (Hayashida et al. 2003; Lee et al. 2006; Fujita et al. 2004). Our data of immediate ERK1/2 signal activation in TGF- $\beta$ stimulated IEC-6 cell differentiation are consistent with data acquired from other cell types.

In summary, we demonstrated that growth factor TGF- $\beta$ stimulated small intestinal crypt cell (IEC-6) differentiation. miR-146b up-regulation in part constitutes the intracellular negative feedback loop of TGF- $\beta$ signal involving Smad7 (Fig. 7). Our findings implicate an emerging role of microRNA in gut growth and warrant greater efforts to uncover microRNAs as diagnostic markers or therapeutic targets in gut diseases.

Acknowledgments The authors would like to thank the support of the UC Davis Clinical Nutrition Research Unit (funded by NIH DK
35747) for real-time Q-PCR analyses; Dr. Christopher Barker, Dr. YanXia Hao, Gladstone Institute Genomics Core for microRNA array analysis; Dr. Alisha K. Holloway, Gladstone Institute Bioinformatics Core for statistical analysis. This study was funded by Mead Johnson Nutrition Global Discovery Project, grant number 09000313.

Conflict of interest The authors do not have any conflict of interests.

\section{References}

Barnard JA, Beauchamp RD, Coffey RJ, Moses HL (1989) Regulation of intestinal epithelial cell growth by transforming growth factor type beta. Proc Natl Acad Sci USA 86:1578-1582

Brennecke J, Stark A, Russell RB, Cohen SM (2005) Principles of microRNA-target recognition. PLoS Biol 3:e85

Carroll KM, Wong TT, Drabik DL, Chang EB (1988) Differentiation of rat small intestinal epithelial cells by extracellular matrix. Am J Physiol 254:G355-G360

Chang Y, Ueng SW, Lin-Chao S, Chao CC (2008) Involvement of Gas7 along the ERK1/2 MAP kinase and SOX9 pathway in chondrogenesis of human marrow-derived mesenchymal stem cells. Osteoarthr Cartil 16:1403-1412

Chen YT, Kitabayashi N, Zhou XK, Fahey TJ 3rd, Scognamiglio T (2008) MicroRNA analysis as a potential diagnostic tool for papillary thyroid carcinoma. Mod Pathol 21:1139-1146

Cheng H, Leblond CP (1974) Origin, differentiation and renewal of the four main epithelial cell types in the mouse small intestine. $\mathrm{V}$. Unitarian theory of the origin of the four epithelial cell types. Am J Anat 141:537-561

Daoud G, Amyot M, Rassart E, Masse A, Simoneau L, Lafond J (2005) ERK1/2 and p38 regulate trophoblasts differentiation in human term placenta. J Physiol 566:409-423

Doench JG, Sharp PA (2004) Specificity of microRNA target selection in translational repression. Genes Dev 18:504-511

Edgar R, Domrachev M, Lash AE (2002) Gene expression omnibus: NCBI gene expression and hybridization array data repository. Nucleic Acids Res 30:207-210

Fuchshofer R, Stephan DA, Russell P, Tamm ER (2009) Gene expression profiling of TGFbeta2- and/or BMP7-treated trabecular meshwork cells: Identification of Smad7 as a critical inhibitor of TGF-beta2 signaling. Exp Eye Res 88:1020-1032

Fujita H, Omori S, Ishikura K, Hida M, Awazu M (2004) ERK and p38 mediate high-glucose-induced hypertrophy and TGF-beta expression in renal tubular cells. Am J Physiol Renal Physiol 286:F120-F126

Fulci V, Colombo T, Chiaretti S, Messina M, Citarella F, Tavolaro S, Guarini A, Foà R, Macino G (2009) Characterization of B- and T-lineage acute lymphoblastic leukemia by integrated analysis of MicroRNA and mRNA expression profiles. Genes Chromosom Cancer 48:1069-1082

Gendron FP, Mongrain S, Laprise P, McMahon S, Dubois CM, Blais M, Asselin C, Rivard N (2006) The CDX2 transcription factor regulates furin expression during intestinal epithelial cell differentiation. Am J Physiol Gastrointest Liver Physiol 290:G310-G318

Germani A, Prabel A, Mourah S, Podgorniak MP, Di Carlo A, Ehrlich R, Gisselbrecht S, Varin-Blank N, Calvo F, Bruzzoni-Giovanelli $\mathrm{H}$ (2003) SIAH-1 interacts with CtIP and promotes its degradation by the proteosome pathway. Oncogene 22:8845-8851

Hayashida T, Decaestecker M, Schnaper HW (2003) Cross-talk between ERK MAP kinase and Smad signaling pathways enhances TGF-beta-dependent responses in human mesangial cells. FASEB J 17:1576-1578 
House CM, Möller A, Bowtell DD (2009) Siah proteins: novel drug targets in the Ras and hypoxia pathways. Cancer Res 69:88358838

Hu X, Jin L, Feng L (2004) Erk1/2 but not PI3K pathway is required for neurotrophin 3-induced oligodendrocyte differentiation of post-natal neural stem cells. J Neurochem 90:1339-1347

Hurst DR, Edmonds MD, Scott GK, Benz CC, Vaidya KS, Welch DR (2009) Breast cancer metastasis suppressor 1 up-regulates miR146, which suppresses breast cancer metastasis. Cancer Res 69:1279-1283

Itoh S, ten Dijke P (2007) Negative regulation of TGF-beta receptor/ Smad signal transduction. Curr Opin Cell Biol 19:176-184

Johnsen SA, Subramaniam M, Monroe DG, Janknecht R, Spelsberg TC (2002) Modulation of transforming growth factor beta (TGFbeta)/Smad transcriptional responses through targeted degradation of TGFbeta-inducible early gene-1 by human seven in absentia homologue. J Biol Chem 277:30754-30759

Kim YJ, Hwang SJ, Bae YC, Jung JS (2009) MiR-21 regulates adipogenic differentiation through the modulation of TGF-beta signaling in mesenchymal stem cells derived from human adipose tissue. Stem Cells 27:3093-3102

Kolinska J, Lisa V, Clark JA, Kozakova H, Zakostelecka M, Khailova L, Sinkora M, Kitanovicova A, Dvorak B (2008) Constitutive expression of IL-18 and IL-18R in differentiated IEC-6 cells: effect of TNF-alpha and IFN-gamma treatment. J Interferon Cytokine Res 28:287-296

Koo BK, Lim HS, Chang HJ, Yoon MJ, Choi Y, Kong MP, Kim CH, Kim JM, Park JG, Kong YY (2009) Notch signaling promotes the generation of EphrinB1-positive intestinal epithelial cells. Gastroenterology 137:145-155, e141-e143

Lee SW, Choi KY, Cho JY, Jung SH, Song KB, Park EK, Choi JY, Shin HI, Kim SY, Woo KM, Baek JH, Nam SH, Kim YJ, Kim HJ, Ryoo HM (2006) TGF-beta2 stimulates cranial suture closure through activation of the Erk-MAPK pathway. J Cell Biochem 98:981-991

Liao Y, Lönnerdal B (2010a) miR-584 mediates post-transcriptional expression of lactoferrin receptor in Caco-2 cells and in mouse small intestine during the perinatal period. Int $\mathbf{J}$ Biochem Cell Biol 42:1363-1369

Liao Y, Lönnerdal B (2010b) Beta-catenin/TCF4 transactivates miR30e during intestinal cell differentiation. Cell Mol Life Sci 67:2969-2978

Liao Y, Lönnerdal B (2010c) Global microRNA characterization reveals that miR-103 is involved in IGF-1 stimulated mouse intestinal cell proliferation. PLoS ONE 5:e12976

Lönnerdal B (2010) Bioactive proteins in human milk: mechanisms of action. J Pediatr 156:S26-S30

Melkamu T, Zhang X, Tan J, Zeng Y, Kassie F (2010) Alteration of microRNA expression in vinyl carbamate-induced mouse lung tumors and modulation by the chemopreventive agent indole-3carbinol. Carcinogenesis 31:252-258

Miyazono K (2000) Positive and negative regulation of TGF-beta signaling. J Cell Sci 113:1101-1109
Mizuno Y, Tokuzawa Y, Ninomiya Y, Yagi K, Yatsuka-Kanesaki Y, Suda T, Fukuda T, Katagiri T, Kondoh Y, Amemiya T, Tashiro H, Okazaki Y (2009) miR-210 promotes osteoblastic differentiation through inhibition of AcvR1b. FEBS Lett 583:2263-2268

Moustakas A, Heldin CH (2009) The regulation of TGFbeta signal transduction. Development 136:3699-3714

Nakao A, Afrakhte M, Morén A, Nakayama T, Christian JL, Heuchel $\mathrm{R}$, Itoh S, Kawabata M, Heldin NE, Heldin $\mathrm{CH}$, ten Dijke P (1997) Identification of Smad7, a TGFbeta-inducible antagonist of TGF-beta signalling. Nature 389:631-635

Olson AD, Pysher T, Bienkowski RS (1991) Organization of intestinal epithelial cells into multicellular structures requires laminin and functional actin microfilaments. Exp Cell Res 192:543-549

Penttila IA (2010) Milk-derived transforming growth factor-beta and the infant immune response. J Pediatr 156:S21-S25

Quaroni A, Wands J, Trelstad RL, Isselbacher KJ (1979) Epithelioid cell cultures from rat small intestine. Characterization by morphologic and immunologic criteria. J Cell Biol 80:248-265

Rodríguez-Serrano F, Ríos A, Marchal JA, Caba O, Martínez-Amat A, Prados J, Melguizo C, Ortiz R, Perán M, Boulaiz H, Vélez C, Alvarez P, Aránega A (2010) Differentiation of intestinal epithelial cells mediated by cell confluence and/or exogenous nucleoside supplementation. Cells Tissues Organs 191:478-488

Rogler CE, Levoci L, Ader T, Massimi A, Tchaikovskaya T, Norel R, Rogler LE (2009) MicroRNA-23b cluster microRNAs regulate transforming growth factor-beta/bone morphogenetic protein signaling and liver stem cell differentiation by targeting Smads. Hepatology 50:575-584

Sancho E, Batlle E, Clevers H (2004) Signaling pathways in intestinal development and cancer. Annu Rev Cell Dev Biol 20:695-723

Sun Q, Zhang Y, Yang G, Chen X, Zhang Y, Cao G, Wang J, Sun Y, Zhang P, Fan M, Shao N, Yang X (2008) Transforming growth factor-beta-regulated miR-24 promotes skeletal muscle differentiation. Nucleic Acids Res 36:2690-2699

van der Flier LG, Clevers H (2009) Stem cells, self-renewal, and differentiation in the intestinal epithelium. Annu Rev Physiol 71:241-260

Wang Z, Chen WW, Li RL, Wen B, Sun JB (2003) Effect of gastrin on differentiation of rat intestinal epithelial cells in vitro. World J Gastroenterol 9:1786-1790

Weissman AM (2001) Themes and variations on ubiquitylation. Nat Rev Mol Cell Biol 2:169-178

Wharton K, Derynck R (2009) TGFbeta family signaling: novel insights in development and disease. Development 136:36913697

Wood SR, Zhao Q, Smith LH, Daniels CK (2003) Altered morphology in cultured rat intestinal epithelial IEC- 6 cells is associated with alkaline phosphatase expression. Tissue Cell 35:47-58

Xia H, Qi Y, Ng SS, Chen X, Li D, Chen S, Ge R, Jiang S, Li G, Chen Y, He ML, Kung HF, Lai L, Lin MC (2009) microRNA-146b inhibits glioma cell migration and invasion by targeting MMPs. Brain Res 1269:158-165 